\title{
Green synthesis from biomass
}

\author{
Paulo M Donate
}

\begin{abstract}
This review describes how to apply green chemistry principles to transform biomass into several types of molecules. On the basis of selected papers published over the last three to four years, it includes the main reactions used to convert renewable feedstocks into chemical products that are potentially applicable as raw materials or synthetic intermediates in fine chemical industries with emphasis on preparative organic synthesis.
\end{abstract}

Keywords: Synthesis; Green chemistry; Biomass; Renewable feedstock

\section{Introduction}

The humankind relies on a wide variety of feedstocks that can be used to produce an array of chemicals. Biomass constitutes an inexpensive renewable resource that is available on a global scale and which can sequester carbon. Several industrial areas have switched to biomass as feedstock, to increase their sustainability and reduce the overall environmental impact. The conversion of biomass into a great variety of valuable chemicals is the key concept of a biorefinery [1-3].

More specifically, biomass includes any organic matter that is available on a renewable or recurring basis, such as energy crops and trees, agricultural food and food crop residues, aquatic plants, wood and residues, animal waste, and other waste materials [3]. Figure 1 shows the main components of biomass, which comprise five categories: starch, cellulose, hemicellulose lignin, and oils [4]. Cellulose, hemicelluloses, and lignin compose the biomass present in wood, grasses, stalks, and straw, for instance. Starch and cellulose are polysaccharides consisting of hexose units; hemicellulose is a heteropolysaccharide made of a mixture of pentose and hexose monomers; lignin is a complex three-dimensional polymer formed by phenolic compounds; and oils consist of triglycerides. Other biomass components, which generally exist in minor amounts and are usually designated secondary metabolites, include alkaloids, carotenoids, flavonoids, phenols, resins, sterols, tannins, terpenes, and waxes, among others [1].

The main components of wood biomass are cellulose ( $35 \%$ to $50 \%$ ), hemicelluloses ( $20 \%$ to $35 \%$ ), lignin (5\% to

Correspondence: pmdonate@usp.br

Departamento de Química, Faculdade de Filosofia, Ciências e Letras de Ribeirao Preto, Universidade de Sao Paulo, Avenida Bandeirantes, 3900, CEP 14404-600 Ribeirao Preto, SP, Brazil
$30 \%)$, and other extracted compounds (1\% to $10 \%)[5,6]$. Although cellulose, hemicelluloses, and lignin transformation has been extensively studied [7-9], less attention has been given to other extracted compounds, which also constitute important feedstocks for commodities and fine chemicals [10]. For example, parts of trees that are normally considered waste contain extracted compounds consisting mainly of resin acids, terpenes, sterols, phenolic substances, lignans, and sugars, among others, which are ultimately valuable for chemical synthesis $[11,12]$. Secondary plant metabolites include essential oils, which have found wide application in the flavor and fragrance industries. Many plant-derived chemicals also constitute secondary metabolites with application in the pharmaceutical field or as non-prescription health supplements [1].

\section{Review}

\section{Biomass conversion}

Ideally, biomass conversion should reduce the use of toxic chemicals and improve the profitability of biorefineries while respecting the environment. Several methods to transform biomass into useful products have been reviewed in recent years [6,13-16].

\section{Lignin conversion}

Lignin represents over $20 \%$ of the total mass of the Earth's biosphere. Using it to obtain chemical feedstocks represents a real challenge in terms of sustainability and environmental protection. The different chemical composition of lignin requires that it be processed separately to obtain phenol derivatives. Alternatively, it could be used as an energy source. According to a survey in the 2007 US Department of Energy, lignin could function as

\section{黑 Springer}




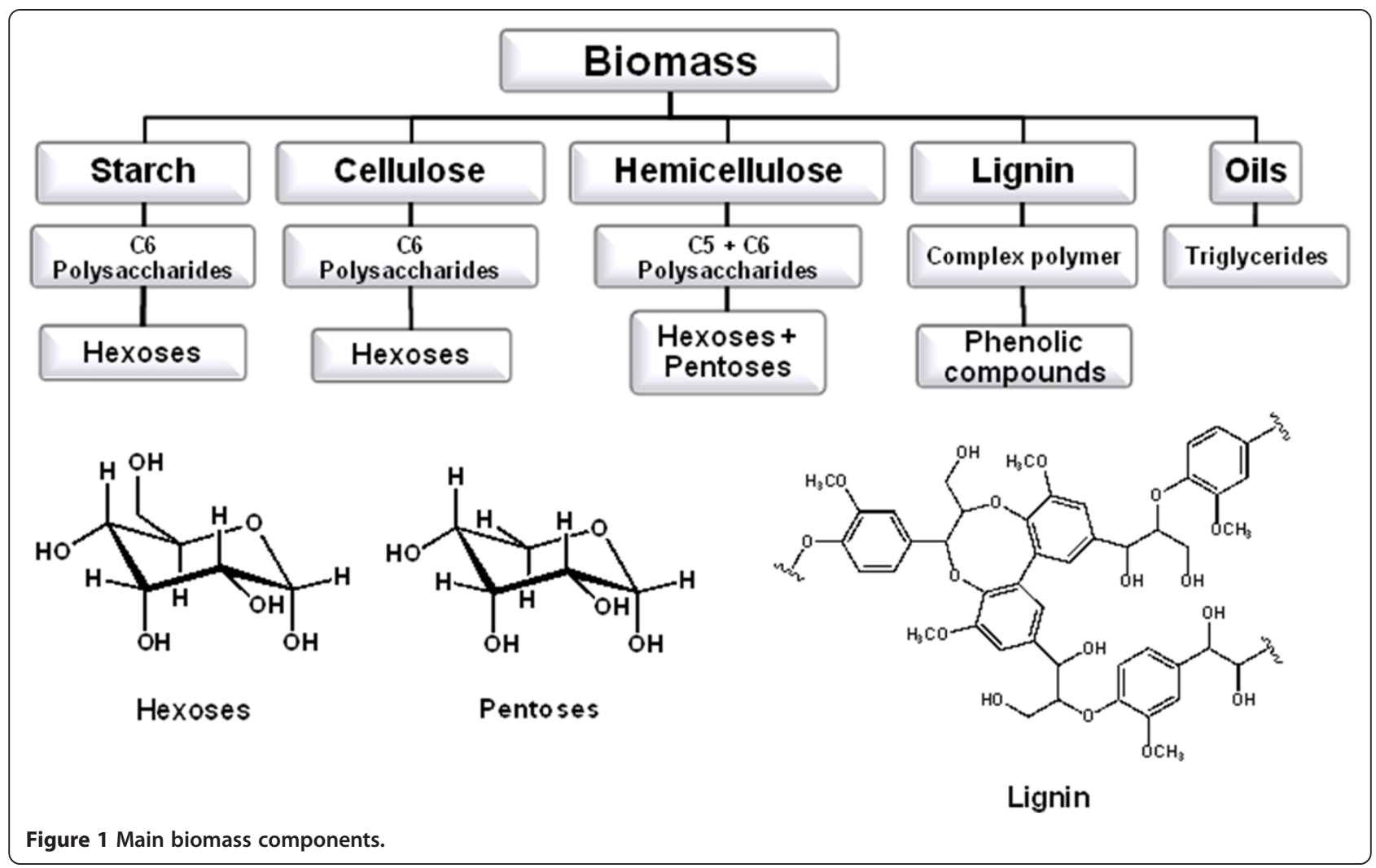

a precursor of valuable chemicals in several ways, mainly to replace oil [17].

Recent articles on the use of lignin have reviewed the different methods that chemists have used to convert this material into chemical compounds with added value. Authors have pointed out the major difficulties encountered while handling lignin; they have also discussed the recent use of ionic liquids [18] as solvents, aiming to provide some new opportunities to efficiently convert lignin into aromatic chemicals with added value [19-23].

\section{Cellulose and hemicelluloses conversion}

Cellulose and hemicelluloses represent the largest part of wood biomass (55\% to $80 \%$ ) [6]. A recently published paper has reviewed the application of ionic liquids to deconstruct and fractionate lignocellulosic biomass [24]. The article focuses on the major advantage of using ionic liquids in the dissolution process as compared with other pretreatment options. Ionic liquids can decrystallize the cellulose portion of lignocellulosic biomass and simultaneously disrupt the lignin and hemicellulose network. This paper [24] also discusses the possibility of removing lignin with the ionic liquid and recovering a separate and possibly more valuable lignin fraction.

Cellulose and hemicelluloses hydrolysis generates monomeric sugar units. These unit and their derivatives can be transformed into a wide range of value-added chemicals. An overview of the chemical transformation of low-molecular weight carbohydrates into products with versatile industrial application profiles has been published [25]. Another article has discussed the chemical catalytic transformations of biomass-derived oxygenated feedstocks (primarily sugars and sugar alcohols) into value-added chemicals and fuels. The key reactions involved in biomass processing are hydrolysis, dehydration, isomerization, aldol condensation, reforming, hydrogenation, and oxidation [26].

The simplified scheme of a chemocatalytic biorefinery presented in Figure 2 is part of an article that has analyzed alternative routes to catalytically transform lignocellulosic materials [27].

Catalytic lignocellulose hydrolysis converts cellulose and hemicellulose into small oligomers and sugars; lignin separates from the mixture. Selective catalytic hydrodeoxygenation (HDO) transforms part of the small oligomers into biofuels or chemicals. Sugar fermentation via the known routes gives ethanol or other several higher-chain alcohols. Part of the sugars can also be converted to hydrocarbons following the aqueous phase reforming, or adapted to produce the biohydrogen that is necessary in many steps of furfural upgrading. Because furfurals show higher chemical functionality and reactivity, it is easier to catalytically upgrade them 


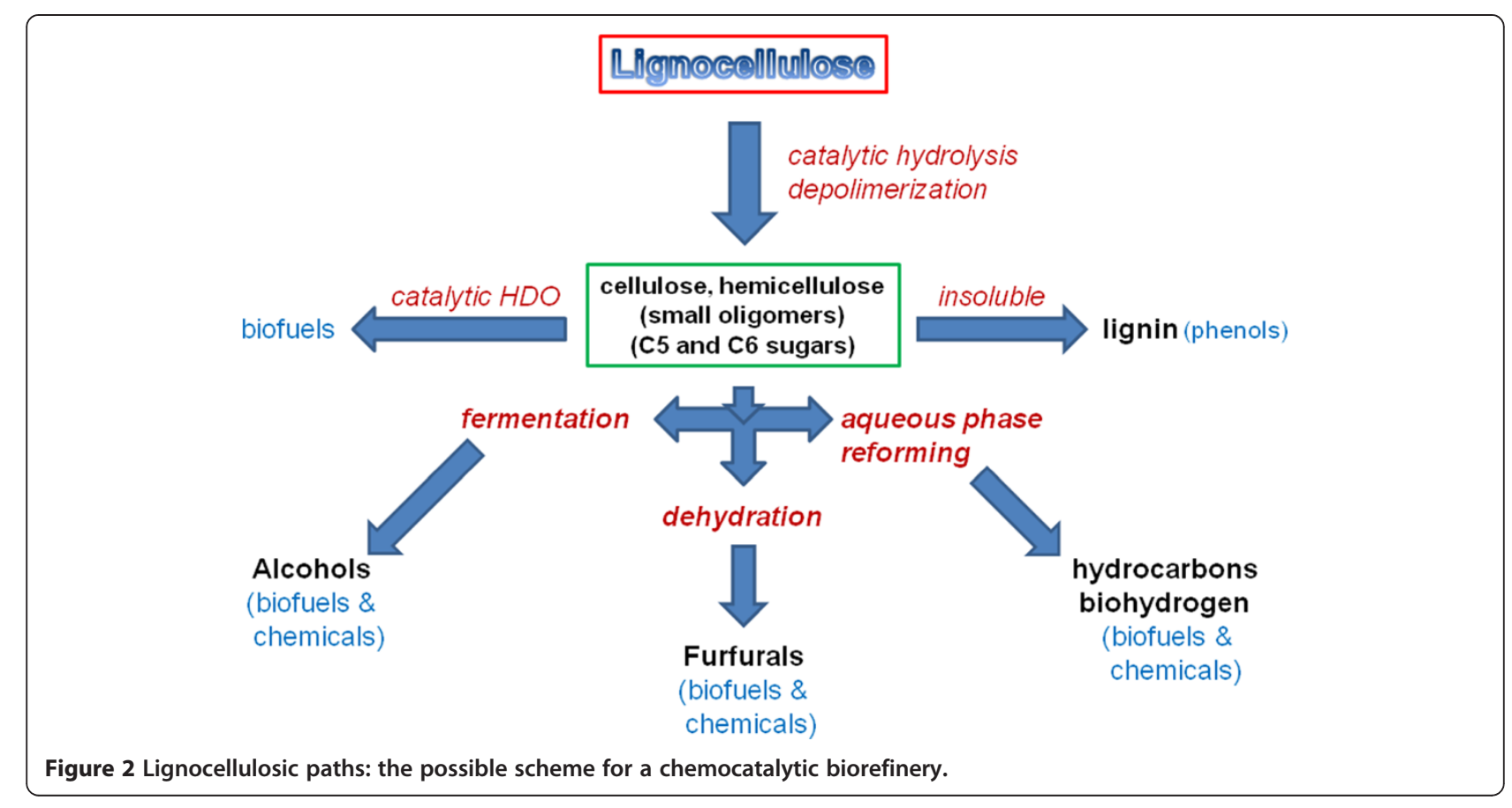

to a variety of value-added products. For example, catalytic hydrogenation/hydrogenolysis of furfural and 5hydroxymethyl-2-furfural (HMF) produces 2-methylfuran and 2,5-dimethylfuran, respectively, both of which display high octane number and good miscibility with gasoline [27].

Scheme 1 lists some typical fine chemicals and fuels produced via cellulose chemocatalytic conversion by different chemical processes [28]. The catalytic conversion of lignocellulosic biomass generates a variety of chemicals, as well as some fuels.

A recent review article has reported on the synthesis and use of sugar derivatives originating from cellulose and hemicellulose using various methodologies [29]. Another critical review has recently discussed the various strategies for the valorization of waste biomass to platform chemicals, and the developments in chemical and biological catalysis [30].

\section{5-Hydroxymethyl-2-furfural production and transformation} Among the several building blocks derived from renewable resources, HMF has been identified as a very promising building block. [5,13,31,32]. HMF possesses two functionalities attached to a furan ring. These functionalities aid HMF conversion into several value-added compounds that are useful in a wide variety of chemical manufacturing applications and industrial products [32-38]. HMF can also be transformed into many specific molecules [32], such as the natural herbicide $\delta$-aminolevulinic acid [39] and the active pharmaceutical ingredient ranitidine (Zantac) [40].

The most desirable route to produce HMF involves widely available biorenewable resources like cellulose $[41,42]$. However, achieving efficient direct transformation of cellulose into HMF seems less feasible $[5,13]$. Most frequently, the synthetic route used to obtain HMF relies on a multistep approach comprising cellulose hydrolysis to glucose, glucose isomerization to fructose, and fructose dehydration to HMF. A broader range of efficient catalysts has been reported to promote fructose dehydration to HMF $[35,43]$. The transformation can also take place in the absence of a catalyst, using specific solvents, such as ionic liquids, to promote the reaction [35].

The specific properties of HMF, such as its high solubility in aqueous media and polar solvents as well as its thermal and chemical instability, make its isolation from the reaction mixture a very important issue. These factors complicate large-scale HMF isolation by solvent extraction or distillation. In fact, the majority of literature papers have reported HMF conversion and/or yields on the basis of HPLC analysis of the reaction mixture rather than isolated yields [35].

Crystallization is one of the best separation processes to use in the industry. Hence, easy-to-crystallize, little volatile solids have been used as reaction media (tetraethylammonium bromide) to produce HMF under homogeneous conditions. In this situation, the reaction medium melts, and the carbohydrates solubilize at the 


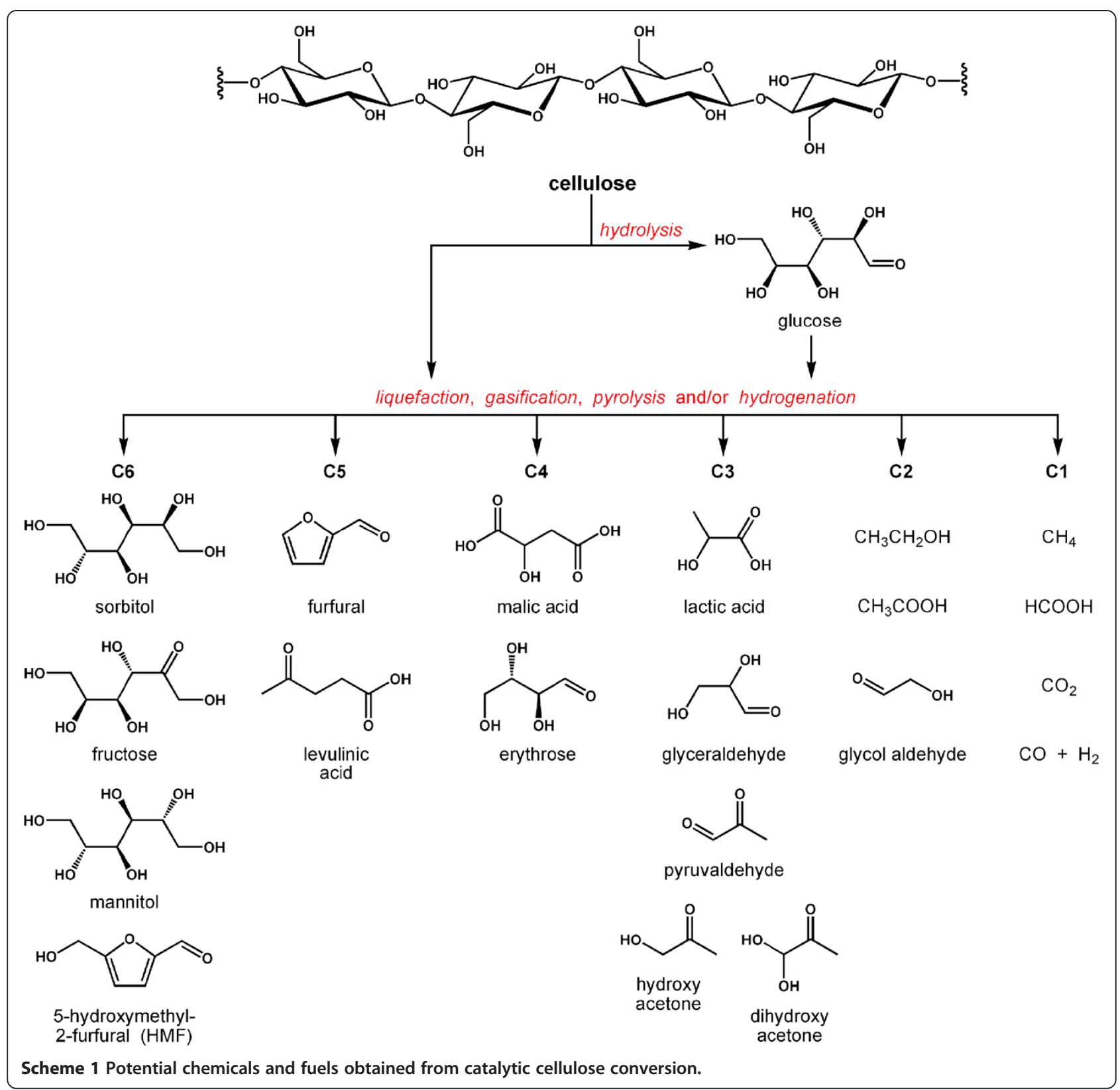

temperature required for the reaction [41]. After cooling, addition of an appropriate and renewable organic solvent (ethanol and ethyl acetate) should prompt precipitation at room temperature. Filtration and evaporation of the reusable organic solvent favors HMF isolation in the mother liquor (see Scheme 2).

\section{Furan conversion into ketones and n-alkanes}

The furan aldehydes derived from hexoses and pentoses offer pathways for the desired chain extensions via aldol condensation $[44,45]$. Coupling these aldehydes with other biomass-derived carbon units using aldol condensation chemistry constitutes an attractive route toward fuel precursors of sufficient energy density.

The use of water-soluble organocatalysts (piperidine or pyrrolidinium acetate) to provide the selective chain extension of HMF has been reported recently [46]. Scheme 3 shows that compounds $\mathbf{1}$ and $\mathbf{2}$ originate from aldol condensation between HMF and acetone.

Removing the exocyclic double bond within these classes of molecules is the key step to achieve successful hydrodeoxygenation later because this process prevents the substrate from fragmenting via retro-aldol reaction in the aqueous reaction medium. Exocyclic double-bond 


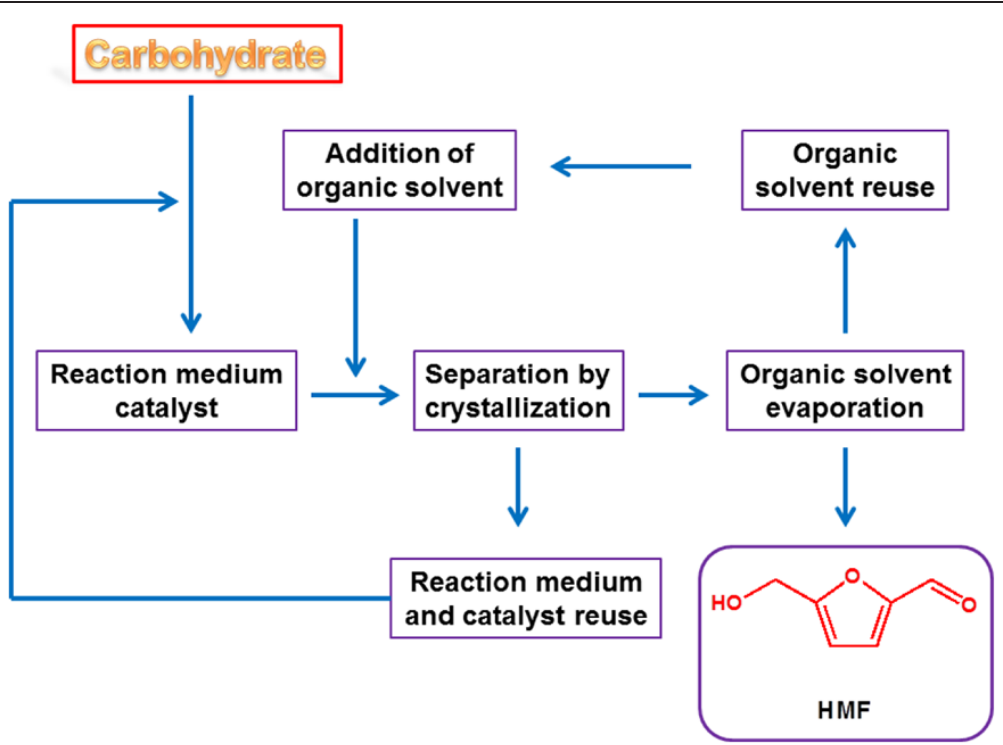

Scheme 2 Integrated approach for HMF production and isolation from carbohydrates (From ref. [41]).

removal occurs by using a palladium catalyst, under 1 to 4 atm of hydrogen in a $50 \%$ aqueous acetic acid solution, to give the saturated products in quantitative yield [45]. Addition of $\mathrm{La}(\mathrm{OTf})_{3}$ to a mixture of the $\mathrm{Pd} / \mathrm{C}$ catalyst, acetic acid, and the ketone, followed by heating at $200^{\circ} \mathrm{C}$ under hydrogen pressures up to 20 to $30 \mathrm{~atm}$ for $12 \mathrm{~h}$, promotes hydrodeoxygenation and subsequent conversion into the corresponding $n$-alkane (see Scheme 4).

\section{Applying the green chemistry principles to synthesis from biomass}

Producing green chemicals from renewable resources is a very broad topic [1,47-50]. Several reviews have focused on developments achieved over the last years with respect to (1) renewable biomass as a source of chemicals, (2) possible conversion pathways, and (3) obtained products [51-53].

The literature survey indicates that the benefits for green chemistry depend upon feedstocks, processes, and products. Processes requiring too many conversion and separation steps affect the overall atom economy, energy demand, and waste emissions [54]. Due to the heterogeneous composition of renewables, clean and energyefficient separation and purification technologies are very important [55]. Biomass conversion processes that involve one or few steps and do not call for separation of the intermediates are certainly more efficient in terms of biomass utilization and waste minimization as compared with the traditional approach [56].

The literature contains countless examples of green chemistry-compatible biomass conversion to end-products via one-pot catalytic processes $[55,56]$. Scheme 5 illustrates the one-pot conversion of the wheat bran syrup to a mixture of alkyl-pentoside surfactants by reaction of the syrup with $n$-decanol in the presence of diluted sulfuric acid aqueous solution at $90^{\circ} \mathrm{C}$ [57]. The unpurified mixture of alkyl-pentosides (5 and 6) displays good surface tension properties

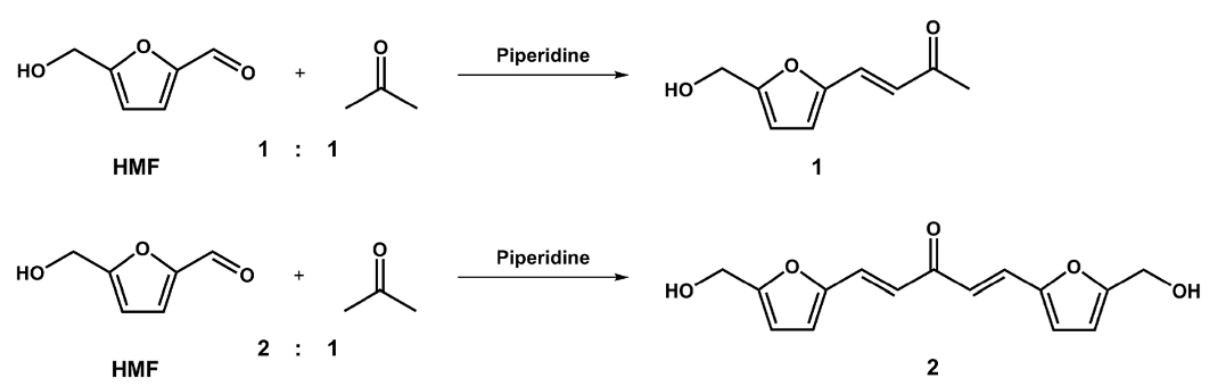

Scheme 3 Organocatalyzed routes to chain-extended furfurals. 


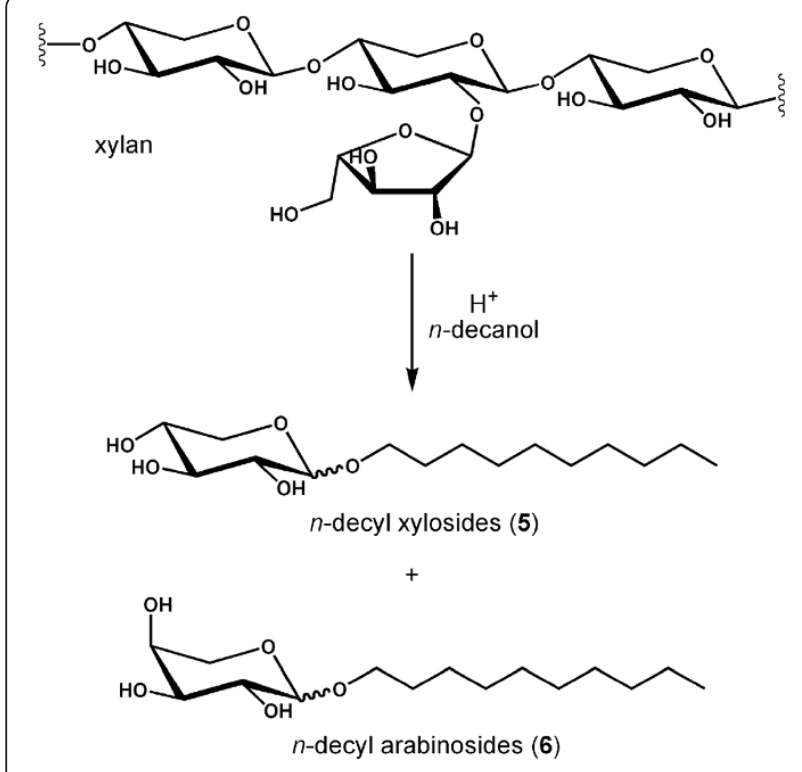

Scheme 5 One-pot wheat bran conversion to alkyl-pentosides (5 and 6).

and is potentially applicable as a low-cost, non-toxic, biodegradable surfactant suitable for dishwashing and laundry purposes [58].

The literature also brings reports on a variety of more complex molecular architectures [56]. A critical review focusing on the preparation of bio-based surfactants in which the carbon atoms are derived from renewable feedstocks has been recently published [59].

A recent and interesting paper [60] has described the use of orange peel waste as raw material to perform a simple and facile one-pot synthesis of fluorescent carbon dots using the hydrothermal carbonization method in aqueous medium, at mild temperature (see Figure 3).
This procedure constitutes an easy and eco-friendly method that may be feasible for large-scale production.

\section{Alternative processes}

The use of microwave heating to conduct chemical transformations has increased over the last years [1]. Microwave energy is attractive in the area of chemistry because it elicits highly efficient energy transfer and selectivity, which reduces reaction time significantly [61,62].

A very recent paper [63] has described an unprecedented catalyst and a solvent-free protocol for the microwave-assisted acetalization of glycerol and carbonyl compounds. High yields of cyclic acetals or ketals have been achieved, including commercially valuable hyacinth fragrance and fuel additive precursors. This methodology does not require excessive amount of solvents or precious catalysts, and it provides a clean and green approach towards glycerol valorization.

Ultrasound is another important alternative energy with application in chemical processes. Sonochemistry, the chemical effects and applications of ultrasonic waves, aims to reduce energy consumption. This process increases product selectivity. Ultrasound has been applied in a number of fields [64], which is conveniently discussed in the book recently edited by Xie and Gathergood [56].

\section{Conclusions}

Many research groups have contributed to increasing the application of green chemistry principles to biomass handling over the last few years. Chemists and chemical companies have been actively searching for greener alternatives that can replace their current manufacturing practices. Significant progress has been made in several key research areas, such as the use of new multifunctional catalysts, environmentally benign solvents, ionic liquids prepared from renewable biomaterials, and alternative energy, especially microwave radiation. All these

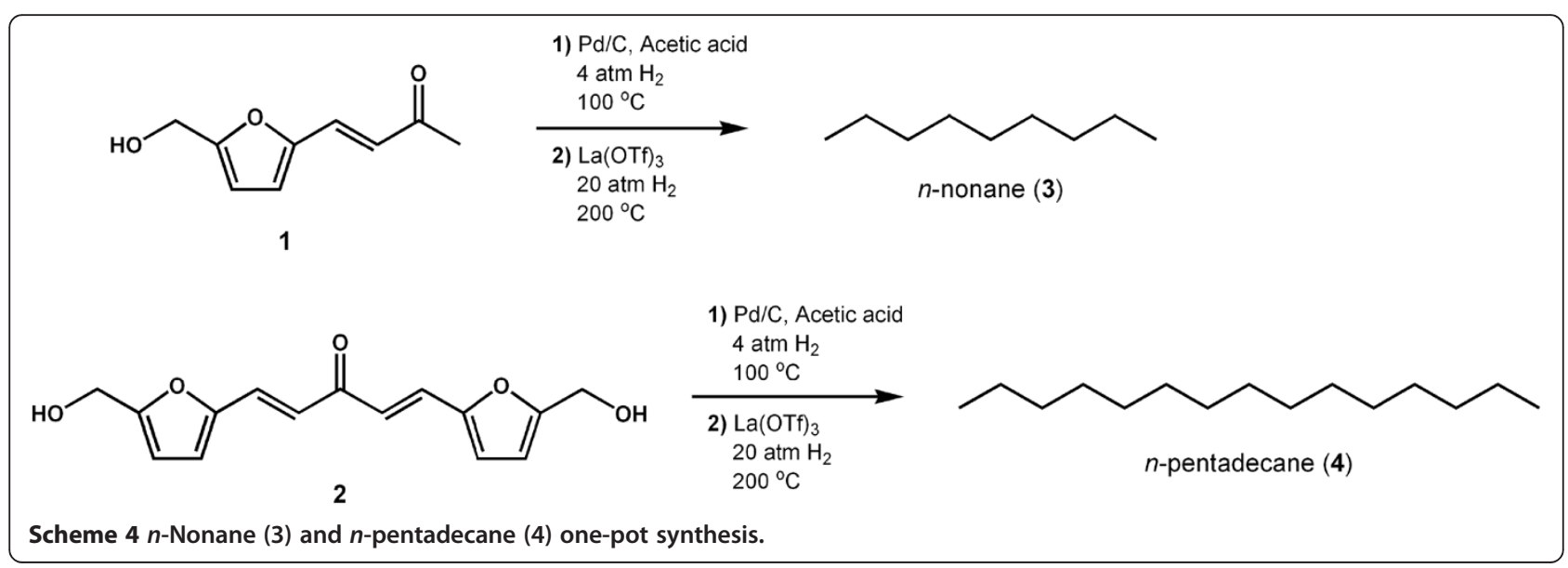




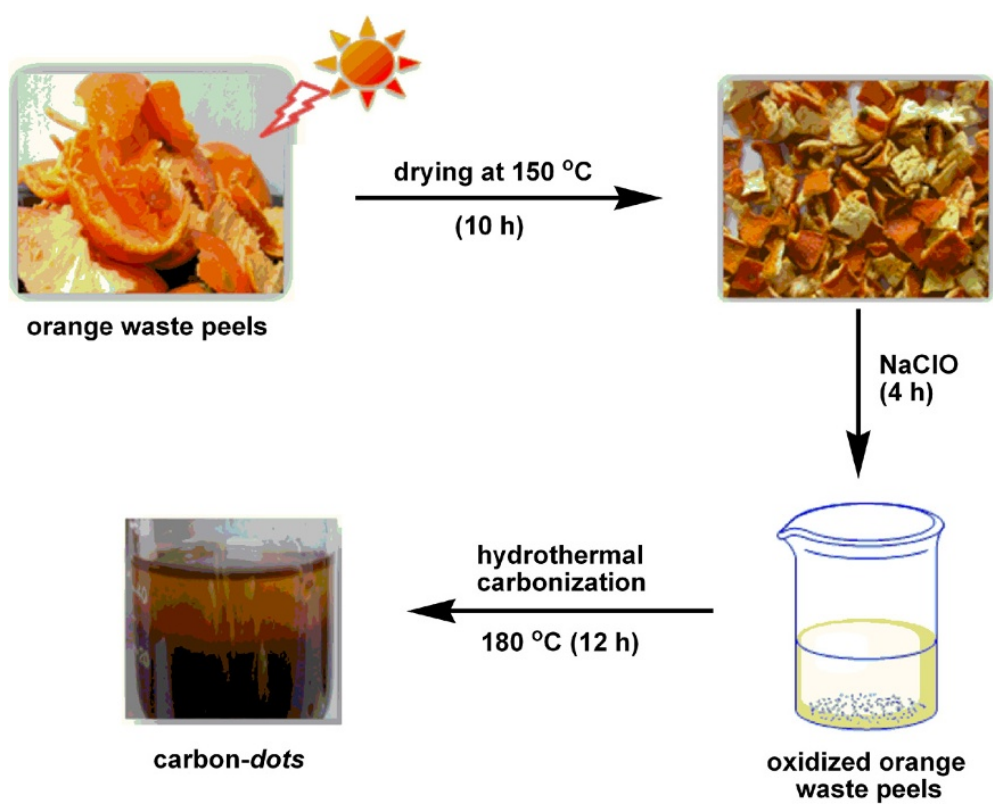

Figure 3 Formation of carbon dots from the hydrothermal treatment of orange peel waste (From ref. [60]).

initiatives should help to develop a new chemical industry based on renewable feedstocks.

However, some technical challenges remain. Designing technologies that enable analysis of the chemical processes developed in the laboratory is mandatory. It is also necessary to improve separation methods and to optimize process and energy efficiency.

\section{Competing interests}

The author declares that they have no competing interests.

Received: 25 March 2014 Accepted: 16 June 2014

Published online: 27 August 2014

\section{References}

1. Clark J, Deswarte F (eds) (2008) Introduction to chemicals from biomass. Wiley, Chichester

2. Daoutidis P, Kelloway A, Marvin WA, Rangarajan S, Torres Al (2013) Process systems engineering for biorefineries: new research vistas. Curr Opin Chem Eng 2:442-447

3. Biorefineries (2005) Industrial processes and products. In: Ullmann's encyclopedia of industrial chemistry, vol 4. Wiley-VCH, Weinheim, pp. 101-133

4. Rubin EM (2008) Genomics of cellulosic biofuels. Nature 454:841-845

5. Huber GW, Iborra S, Corma A (2006) Synthesis of transportation fuels from biomass: chemistry, catalysts, and engineering. Chem Rev 106:4044-4098

6. Mäki-Arvela P, Holmbom B, Salmi T, Murzin DY (2007) Recent progress in synthesis of fine and specialty chemicals from wood and other biomass by heterogeneous catalytic processes. Catal Rev 49:197-340

7. Silva SPM, Lopes AMC, Roseiroa LB, Bogel-Łukasik R (2013) Novel pretreatment and fractionation method for lignocellulosic biomass using ionic liquids. RSC Advances 3:16040-16050

8. van Spronsen J, Cardoso MAT, Witkamp GJ, Jong W, Kroon MC (2011) Separation and recovery of the constituents from lignocellulosic biomass by using ionic liquids and acetic acid as co-solvents for mild hydrolysis. Chem Eng Process 50:196-199

9. Zavrel M, Bross D, Funke M, Büchs J, Spiess AC (2009) High-throughput screening for ionic liquids dissolving ligno-cellulose. Bioresour Technol 100:2580-2587
10. Wang Y, Libin Wu L, Wang C, Yu J, Yang Z (2011) Investigating the influence of extractives on the oil yield and alkane production obtained from three kinds of biomass via deoxy-liquefaction. Bioresour Technol 102:7190-7195

11. Silveira CV, Trevisan MTS, Rios JB, Erben G, Haubner R, Pfundstein B, Owen RW (2010) Secondary plant substances in various extracts of the leaves, fruits, stem and bark of Caraipa densifolia Mart. Food Chem Toxicol 48:1597-1606

12. Lin TC, Fang JM, Cheng YS (1999) Terpenes and lignans from leaves of Chamaecyparis formosensis. Phytochemistry 51:793-801

13. Corma A, Iborra S, Velty A (2007) Chemical routes for the transformation of biomass into chemicals. Chem Rev 107:2411-2502

14. Budroni G, Corma A (2008) Gold and gold-platinum as active and selective catalyst for biomass conversion: synthesis of gamma-butyrolactone and one-pot synthesis of pyrrolidone. J Catal 257:403-408

15. Chheda JN, Dumesic JA (2007) An overview of dehydration, aldolcondensation and hydrogenation processes for production of liquid alkanes from biomass-derived carbohydrates. Catal Today 123:59-70

16. Moiseev II (2013) Green chemistry: development trajectory. Russ Chem Rev 82:616-623

17. Holladay JE, Bozell JJ, White JF, Johnson D (2007) Top value added chemicals from biomass Volume $\|$ - results of screening for potential candidates from biorefinery lignin. U.S. Department of Energy, Washington DC

18. Liu QP, Hou XD, Li N, Zong MH (2012) Ionic liquids from renewable biomaterials: synthesis, characterization and application in the pretreatment of biomass. Green Chem 14:304-307

19. Lu Y, Wey XY, Zong ZM, Lu YC, Zhao W, Cao JP (2013) Structural investigation and application of lignins. Prog Chem 25:838-858

20. Varanasi P, Singh P, Auer M, Adams PD, Simmons BA, Singh S (2013) Survey of renewable chemicals produced from lignocellulosic biomass during ionic liquid pretreatment. Biotechnol Biofuels 6:14-23

21. Chatel G, Rogers RD (2014) Oxidation of lignin using ionic liquids - an innovative strategy to produce renewable chemicals. ACS Sustainable Chem Eng 2:322-339

22. Yang L, Seshan K, Li Y (2013) Transetherification of guaiacol to o-ethoxyphenol with gamma Al2O3 as a catalyst in supercritical ethanol. Catal Commun 30:36-39

23. Yang L, Zhou W, Seshan K, Li Y (2013) Green and efficient synthesis route of catechol from guaiacol. J Mol Catal A: Chemical 368-369:61-65

24. Brandt A, Gräsvik J, Hallett JP, Welton T (2013) Deconstruction of lignocellulosic biomass with ionic liquids. Green Chem 15:550-583 
25. Lichtenthaler FW, Peters S (2004) Carbohydrates as green raw materials for the chemical industry. C R Chimie 7:65-90

26. Chheda JN, Huber GW, Dumesic JA (2007) Liquid-phase catalytic processing of biomass-derived oxygenated hydrocarbons to fuels and chemicals. Angew Chem Int Ed 46:7164-7183

27. Centi G, Lanzafame P, Perathoner S (2011) Analysis of the alternative routes in the catalytic transformation of lignocellulosic materials. Catal Today 167:14-30

28. Zhou CH, Xia X, Lin CX, Tong DS, Beltramini J (2011) Catalytic conversion of lignocellulosic biomass to fine chemicals and fuels. Chem Soc Rev 40:5588-5617

29. Kobayashi H, Fukuoka A (2013) Synthesis and utilisation of sugar compounds derived from lignocellulosic biomass. Green Chem 15:1740-1763

30. Sheldon RA (2014) Green and sustainable manufacture of chemicals from biomass: state of the art. Green Chem 16:950-963

31. Lewkowski J (2001) Synthesis, chemistry and applications of 5-hydroxymethylfurfural and its derivatives. ARKIVOC 2:17-54

32. van Putten RJ, van der Waal JC, Rasrendra CB, Heeres HJ, de Viers JG (2013) Hydroxymethylfurfural, a versatile platform chemical made from renewable resources. Chem Rev 113:1499-1597

33. Stahlberg T, Fu W, Woodley JM, Riisager A (2011) Synthesis of 5-(hydroxymethyl)-furfural in ionic liquids: paving the way to renewable chemicals. ChemSusChem 4:451-458

34. Climent MJ, Corma A, Iborra S (2011) Converting carbohydrates to bulk chemicals and fines chemicals over heterogeneous catalysts. Green Chem 13:520-540

35. Rosatella AA, Simeonov SP, Frade RFM, Afonso CAM (2011) 5-Hydroxymethylfurfural (HMF) as a building block platform: biological properties, synthesis and synthetic applications. Green Chem 13:754-793

36. Zakrzewska ME, Bogel-Lukasik E, Bogel-Lukasik R (2011) lonic liquidmediated formation of 5-hydroxymethylfurfural - a promising biomass-derived building block. Chem Rev 111:397-417

37. Dutta S, De S, Saha B (2012) A brief summary of the synthesis of polyester building-block chemicals and biofuels from 5-hydroxymethylfurfural. ChemPlusChem 77:259-272

38. Buntara T, Noel S, Phua PH, Melián-Cabrera I, de Vries JG, Heeres HJ (2012) From 5-hydroxymethylfurfural (HMF) to polymer precursors: catalyst screening studies on the conversion of 1,2,6-hexanetriol to 1,6-hexanediol. Top Catal 55:612-619

39. Mascal M, Dutta S (2011) Synthesis of the natural herbicide $\delta$-aminolevulinic acid from cellulose-derived 5-(chloromethyl)furfural. Green Chem 13:40-41

40. Mascal M, Dutta S (2011) Synthesis of ranitidine (Zantac) from cellulosederived5-(chloromethyl)furfural. Green Chem 13:3101-3102

41. Simeonov SP, Coelho JAS, Afonso CAM (2012) An integrated approach for the production and isolation of 5-hydroxymethylfurfural from carbohydrates. ChemSusChem 5:1388-1391

42. Abou-Yousef H, Hassan EB, Steele P (2013) Rapid conversion of cellulose to 5-hydroxymethylfurfural using single and combined metal chloride catalysts in ionic liquid. J Fuel Chem Technol 41:214-222

43. Liu J, Tang Y, Wu K, Bi C, Cui Q (2012) Conversion of fructose into 5hydroxy-methylfurfural (HMF) and its derivatives promoted by inorganic salt in alcohol. Carbohydrate Res 350:20-24

44. Keith JM, Kim JK, Alexander L, Wu R, Martin RL, Batista ER, Michalczyk R, Scott B, Hanson SK, Sutton AD, Gordon JC, Silks LAP (2014) Aqueous organocatalysis for the carbon chain extension of carbohydrate derivatives: application to the production of transportation fuels. Curr Org Chem

45. Silks LA, Gordon JC, Wu R, Hanson SK (2012) Method of carbon chain extension using novel aldol reaction., Patent US20120289720 A1

46. Sutton AD, Waldie FD, Wu R, Schlaf M, Silks LA, Gordon JC (2013) The hydrodeoxygenation of bioderived furans into alkanes. Nature Chem 5:428-432

47. Anastas PT, Warner JC (1998) Green chemistry: theory and practice. Oxford University Press, Oxford

48. Tundo P, Rossi RH (2004) Quimica Verde en Latinoamerica. In: Green Chemistry Series, vol 11, Consorzio Interuniversitario Nazionale "La Chimica per L'Ambiente", Venice, Italy

49. Sheldon RA, Arends IW, Habefeld U (eds) (2007) Green chemistry and catalysis. Wiley-VCH, West Sussex
50. Sharma SK (2010) Green chemistry for environmental sustainability, Advancing sustainability through green chemistry and engineering. CRC Press, Boca Raton

51. Corrêa AG, Zuin VG, Ferreira VF, Vazquez PG (2013) Green chemistry in Brazil. Pure Appl Chem 85:1643-1653

52. Xu Y, Hanna MA, Isom L (2008) Green chemicals from renewable agricultural biomass - a mini review. Open Agric J 2:54-61

53. Sheldon RA (2012) Fundamentals of green chemistry: efficiency in reaction design. Chem Soc Rev 41:1437-1451

54. Ballini R (2009) Eco-friendly synthesis of fine chemicals, Green Chemistry Series. Royal Society of Chemistry Publications, Cambridge

55. Gallezot P (2012) Conversion of biomass to selected chemical products. Chem Soc Rev 41:1538-1558

56. Xie H, Gathergood N (eds) (2013) The role of green chemistry in biomass processing and conversion. John Wiley \& Sons, Hoboken

57. Marinkovic S, Estrine B (2010) Direct conversion of wheat bran hemicelluloses into $n$-decyl-pentosides. Green Chem 12:1929-1932

58. Martel F, Estrine B, Plantier-Royon R, Hoffmann N, Portela C (2010) Development of agriculture left-overs: fine organic chemicals from wheat hemicellulose-derived pentoses. Top Curr Chem 294:79-115

59. Foley P, Kermanshahi A, Beach ES, Zimmerman JB (2012) Derivation and synthesis of renewable surfactants. Chem Soc Rev 41:1499-1518

60. Prasannan A, Imae T (2013) One-pot synthesis of fluorescent carbon dots from orange waste peels. Ind Eng Chem Res 52:15673-15678

61. Loupy A (ed) (2006) Microwaves in organic synthesis, 2nd edn. Wiley-VCH, Weinheim

62. Pistarà V, Rescifina A, Chiacchio MA, Corsaro A (2014) Use of microwave heating in the synthesis of heterocycles from carbohydrates. Curr Org Chem 18:417-445

63. Pawar RR, Jadhav SV, Bajaj HC (2014) Microwave-assisted rapid valorization of glycerol towards acetals and ketals. Chem Eng J 235:61-66

64. Chen D, Sharma SK, Mudhoo A (eds) (2011) Handbook on applications of ultrasound: sonochemistry for sustainability. CRC Press, Boca Raton

doi:10.1186/s40538-014-0004-2

Cite this article as: Donate: Green synthesis from biomass. Chemical and Biological Technologies in Agriculture 2014 1:4.

\section{Submit your manuscript to a SpringerOpen ${ }^{\circ}$ journal and benefit from:}

- Convenient online submission

- Rigorous peer review

- Immediate publication on acceptance

- Open access: articles freely available online

- High visibility within the field

- Retaining the copyright to your article

Submit your next manuscript at $\gg$ springeropen.com 